\title{
Capacidade Tecnológica e Gestão de Resíduos em Empresas de Calçados do Vale do Sinos: Estudo de Dois Casos
}

\author{
Cláudia Viegas \\ Edi Madalena Fracasso
}

\begin{abstract}
RESUMO
O gerenciamento ambiental tem sido visto, especialmente desde o início da atual década, como ferramenta de competitividade. Isto tem ocorrido no contexto da globalização dos mercados, cujas relações de comércio influenciam, de modo determinante, as vantagens competitivas ligadas à diferenciação de produto e à redução de custos. As empresas que se preocupam com a melhoria de seu nível de competitividade, aumentando continuamente sua capacidade tecnológica, supostamente estão mais aptas a adotar o gerenciamento ambiental. Este artigo propõe um modelo de análise da capacidade tecnológica e da gestão de resíduos sólidos para a indústria calçadista, que foi aplicado ao estudo de duas empresas do Vale do Sinos, maior aglomerado brasileiro de produção de calçados. O estudo dos casos mostrou que o modelo proposto é um instrumento útil que deverá ser submetido a novos testes. Conclui-se que as empresas, apesar de enquadráveis no mesmo nível de capacidade tecnológica, apresentam diferenças de desempenho tecnológico capazes de afetar o resultado em termos de gerenciamento de resíduos sólidos industriais. Em outras palavras, melhorias promovidas na capacidade tecnológica condicionam, mas não necessariamente determinam, o bom desempenho em termos de gerenciamento de resíduos sólidos nas empresas.
\end{abstract}

Palavras-chaves: capacidade tecnológica; gerenciamento ambiental; gestão de resíduos sólidos industriais.

\begin{abstract}
The environmental management in the current decade has been seen as a competitivity tool. This happened in the context of the globalization of the economy in which the commerce regulations influenced the competitive advantages linked to the product differentiation and to the cost reduction. It is usually assumed that the enterprises concerned with increasing their competitivity by increasing their technological capability tend to adopt environmental management. This article proposes an analytical model of technological capability and of solid wastes management for the footwear industry in the Sinos Valley, the Brazilian largest cluster of footwear industry production; the high indexes of industrial solid waste generation, as a consequence of the high levels of loss of raw material in the production process, are an economical and an ecological problem for the enterprises of the region. The results showed similarities between the enterprises in what is concerned with technological capability and some differences regarding to environmental management. The research instrument proved to be useful for diagnostic purposes but needs further improvements and testing.
\end{abstract}

Key words: technological capability; environmental management; solid waste management. 


\section{INTRODUÇĀO}

O gerenciamento ambiental tem sido visto, especialmente desde o início da atual década, como ferramenta de competitividade. Isto tem ocorrido no contexto da globalização dos mercados, cujas regulamentações de comércio influenciam, de modo determinante, as vantagens competitivas ligadas à diferenciação de produto e à redução de custos. As empresas que se preocupam com a melhoria de seu nível de competitividade, aumentando continuamente sua capacidade tecnológica - vista como a soma dos conhecimentos e habilidades de seus trabalhadores e gerentes - tendem a adotar gerenciamento ambiental. Isto sugere a existência de vínculos entre capacidade tecnológica e gestão ambiental. Este artigo propõe um modelo de análise de capacidade tecnológica e de gestão de resíduos sólidos para a indústria calçadista.

No Vale do Sinos, maior aglomerado brasileiro de produção de calçados, os altos índices de geração de resíduos sólidos industriais, em conseqüência dos elevados níveis de perda de matérias-primas no processo produtivo, são um problema econômico e ecológico para as empresas da região. Daí a importância de estudos como o presente, que buscam desenvolver instrumentos que permitam o diagnóstico e a proposta de soluções ao problema.

\section{Competitividade, Tecnologia e Gestão Ambiental na Indústria CALÇADISTA}

A busca da competitividade, um dos imperativos do atual cenário econômico, em nível internacional, não pode mais ser dissociada da incorporação de conceitos de progresso técnico que levem em conta as preocupações com o meio ambiente. Esta constatação, feita direta ou indiretamente, é comum a vários autores que estudam a competitividade industrial. Coutinho e Ferraz (1994), por exemplo, citam o meio ambiente como um dos fatores sistêmicos dos quais depende a competitividade em nível nacional, setorial e empresarial. Porter e Linde (1995) destacam a crescente importância da observação de questões ambientais como fatores regulatórios de competitividade para a conquista e manutenção do mercado por parte das empresas.

As chamadas resoluções verdes da OMC são apenas um sinal das mudanças que estão para vir no que diz respeito às relações entre gestão da tecnologia e gestão ambiental nas empresas, principalmente na rotina das que exportam. Ou- 
tro fator que atesta a emergência da interação entre esses dois tipos de gestão é a série de normas ISO 14000, relativas à gestão ambiental. Essas normas, uma vez implantadas, total ou mesmo parcialmente, capacitam as organizações a incorporarem ou desenvolverem as melhores tecnologias para prevenir os problemas ambientais, além de permitirem o estabelecimento de diretrizes para solucionar os existentes.

A gestão ambiental, de certa forma, significa o resgate da responsabilidade subjacente à aplicação de soluções que contenham crescente diferenciação tecnológica, no desafio da preservação ambiental com a manutenção e a abertura de novas possibilidades de desenvolvimento. Pode-se mesmo afirmar que este tipo de gestão depende da capacidade tecnológica, à medida que esta capacidade é entendida "como um processo contínuo de absorção ou criação de conhecimentos técnicos, determinados, em parte, por fatores externos e, em parte, pelo acúmulo de conhecimentos e habilidades" (Lall, 1992, p. 166).

A capacidade tecnológica está ancorada também nos conhecimentos e habilidades internos que a empresa pode gerar ou incorporar para atender exigências de competitividade impostas externamente; a gestão ambiental figura, pelo menos em princípio, como uma exigência externa ou fator sistêmico de competitividade, dependendo do desempenho em termos de capacidade tecnológica. Portanto a avaliação da capacidade tecnológica pode indicar rumos à gestão ambiental. Isto é especialmente válido para setores exportadores, que são hoje os mais visados em termos de exigências no comércio. É o caso da indústria calçadista brasileira, em especial a do Rio Grande do Sul e, particularmente, a do Vale do Sinos, que se destaca por sua forte participação no comércio exterior do Brasil.

Desde que começou a se tornar expressivo na pauta de exportações do Brasil, no final dos anos 60 e início da década de 70, o setor coureiro-calçadista como um todo, incluindo a indústria de calçados, tem participado com uma média anual em torno de 4\% das exportações do país, em volume monetário, chegando, em 1995, à cifra de 1.413.692.550 de dólares, correspondentes a 137.974.434 pares exportados (Abicalçados, 1996).

Nos últimos anos, porém, este desempenho vem sendo abalado devido a fatores como as políticas governamentais de câmbio e de abertura do mercado às importações, que geraram, respectivamente, defasagem nos ganhos dos exportadores e aumento da concorrência do Brasil com países asiáticos na venda do manufaturado ao exterior. Assim, apesar de, nos primeiros oito meses de 1996, ter havido uma tendência ao aumento monetário das exportações, de janeiro a dezembro de 1995, por exemplo, as vendas externas de calçados brasileiros caíram $8 \%$ em volume monetário, e 19\% em valores físicos, relativamente ao mesmo período de 1994 (Abicalçados, 1996). 
Essa crise de competitividade da indústria calçadista coincide com o desafio da gestão ambiental, cuja implementação pode, por sua vez, representar o estabelecimento de estratégias para novos ganhos de competitividade, através de técnicas como racionalização do uso de matérias-primas, reaproveitamento e reciclagem de resíduos. A busca de recuperação das fatias de mercado perdidas, portanto, poderá ser catalisada pela adoção de resoluções verdes, para que as empresas do setor se mantenham competindo.

No plano da gestão ambiental, o problema básico da indústria calçadista brasileira é o elevado volume de resíduos derivados da atividade produtiva, causado pelo alto índice de perdas de matérias-primas no processo produtivo. Estimativas elaboradas por consultores de empresas do ramo apontam que a defasagem entre input - matérias-primas, energia, etc - e output - produtos acabados e resíduos está entre $18 \%$ e $30 \%$ nos processos produtivos do setor. A variação, nessa faixa percentual, deve-se a particularidades de cada empresa no que diz respeito a vários fatores, como escala de produção, métodos de compra e tipos e estágios de matérias-primas empregadas, e seu modo de utilização ao longo do processo produtivo, em função dos tipos de modelagem.

As tentativas de análise global do problema tornam-se difíceis pela inexistência de estatísticas confiáveis sobre o controle das perdas, na maioria das empresas, e pela ausência de estudos que enfoquem os processos produtivo, de treinamento de pessoal e de aquisição de matérias-primas como pontos a serem trabalhados para a redução de desperdícios.

Outro agravante é a variação da composição dos materiais que formam o calçado, em função das exigências de moda. Segundo Costa (1993), o couro, como matéria-prima da indústria calçadista brasileira, teve sua participação reduzida de $37,4 \%$, no início dos anos 70, para 21,4\% em 1990. Isto indica o ingresso dos chamados materiais alternativos na produção de calçados - por exemplo, EVA (etil vinil acetato), TR, SBR (borrachas termoplásticas), PU (poliuretano), PVC (policloreto de vinil), em saltos, solados e viras, e não-tecidos, em forros, avessos e palmilhas - com o objetivo de redução de custos, especialmente na produção voltada ao mercado interno. $\mathrm{O}$ aumento da presença desses materiais, embora possa ser considerado também, em alguns casos, uma exigência de moda, visando à diferenciação do produto, altera substancialmente o perfil da geração de resíduos nas empresas do setor, exigindo tecnologia para classificá-los e dar-lhes o destino tecnicamente adequado. Muitos desses materiais alternativos são hoje considerados não recicláveis devido à inexistência de opções ao mesmo tempo técnica e economicamente viáveis para reciclá-los. Isto implica o aumento das áreas de aterro ou a deposição irregular de resíduos.

O elevado índice de perdas, a dificuldade técnica de reaproveitamento de mate- 
riais e a deposição irregular de resíduos, prática ainda comum a muitas empresas de calçados, são problemas tanto de capacidade tecnológica quanto de gestão ambiental. A resolução desses problemas depende cada vez mais do aumento da capacidade tecnológica, o que equivale a considerar que a gestão de resíduos sólidos em empresas calçadistas pode ser avaliada a partir da análise da capacidade tecnológica dessas empresas.

\section{O Processo de Produção de Calçados e a Geração de Resíduos Sólidos}

O calçado é uma peça do vestuário cujo objetivo principal é a proteção dos pés (Piccinini, 1990). A fabricação do manufaturado segue, em geral, oito etapas:

. Definição do modelo: É a fase de escolha do tipo de usuário, finalidade do calçado, design e tipo de construção. A partir daí são selecionadas as matérias-primas e os componentes a ser empregados na produção. Esta etapa, por ser basicamente uma fase de concepção, não implica a geração de resíduos em volume expressivo, de modo que os possíveis rejeitos dela derivados podem ser desprezados no contexto global do processo.

. Modelagem: Consiste na criação do design, desenvolvimento de fôrmas, destaque das peças, detalhamento da produção e fabricação de amostras (CTCCA/ Sebrae, 1994). Nessa etapa são gerados vários tipos de resíduos, que aparecem ao longo das demais etapas do processo. Os volumes desses rejeitos, porém, não são tão expressivos quanto os derivados da produção em lotes.

. Corte: É realizado de acordo com as escalas da modelagem. Pode ser manual, com moldes; mecânico, com balancins; ou informatizado, através do uso do Computer Aided Design - CAD (CTCCA/Sebrae, 1994). Nesta etapa é gerada a maior parte dos resíduos derivados da fabricação de calçados: aparas de couro curtido e/ou restos de materiais sintéticos utilizados em cabedais e/ou solados, como, por exemplo, o EVA. Navalhas inutilizadas também derivam desta fase do processo.

. Chanfração: Consiste no desgaste das peças do calçado, a fim de facilitar os processos de colagem e montagem. Os principais resíduos desta etapa são pós de couro curtido ou de outros materiais alternativos, já descritos.

. Costura e preparação: A costura consiste em unir as peças do cabedal, primeiro com adesivo e depois com máquina - numa operação chamada pesponto. Dobras, picotes e viras também são feitos nessa etapa, da qual as peças saem 
preparadas para a montagem (CTCCA/Sebrae, 1994). Restos de linhas e de adesivos, pequenos pedaços de couro e/ou de materiais sintéticos são os resíduos mais comuns nessa etapa.

. Pré-fabricação: É a montagem ou produção de todos os componentes de sustentação básica do calçado - solado, palmilha de montagem, contraforte e couraça (CTCCA/Sebrae, 1994). Nem todas as empresas contam com esta etapa - algumas preferem comprar componentes prontos. Da produção do solado, derivam resíduos como aparas de couro e restos de materiais sintéticos derivados de corte ou de processos de injeção. Da produção da palmilha, do contraforte e da couraça derivam restos de couro e/ou de materiais conhecidos como não-tecidos, espumas, nylon, poliéster, etc.

. Montagem: Consiste na união entre o cabedal e os componentes do solado. Os principais resíduos sólidos da montagem são: restos de pregos e tachas, panos, estopas e pincéis sujos com produtos químicos e restos de solventes, tintas e produtos químicos diversos.

. Acabamento: Consiste em várias operações para deixar o calçado com boa aparência: limpeza, pintura, aplicação de cera, escovação (CTCCA/Sebrae, 1994). Os resíduos desta etapa são semelhantes aos da montagem, exceto no que diz respeito aos metais.

\section{Indicadores de Capacidade Tecnológica e Enfoques de Gestão AMBIENTAL}

Lall (1992) identifica três tipos de capacidade tecnológica, de acordo com as funções a que se referem na empresa:

. capacidade tecnológica básica ou de produção;

. capacidade tecnológica intermediária ou de vínculos;

. capacidade tecnológica avançada ou de investimento.

Esta classificação é cumulativa, o que significa que uma empresa pode, através do acúmulo e do desenvolvimento de habilidades e conhecimentos, passar de uma capacidade básica para uma intermediária ou avançada. No caso da indústria calçadista brasileira, os níveis de capacidade tecnológica podem ser estabelecidos com base na adaptação da classificação de Lall (1992) à síntese de alguns resultados de estudos envolvendo o tema tecnologia e competitividade do setor, realizados entre 1976 e 1995 pelos seguintes autores: Cruz (1976), Gomes Neto e 
Figueiredo (1982), Ruas (1985), Silveira (1986), Moreira (1987), Piccinini (1990, 1991, 1993), Alves Filho (1991), Sebrae/SCT (1992), Ruas e Antunes (1992), Costa (1993), Zawislak (1994), Reis (1994) e Noer (1995). Para estabelecer a proposta de análise de capacidade tecnológica da indústria calçadista, foram identificados, nesses estudos, aspectos relativos aos seguintes itens: produto; etapas do processo (já descritas); aspectos do processo (mecanização, organização do trabalho, qualificação dos trabalhadores e formalização de procedimentos); realização de vínculos; realização de investimentos.

Já em relação aos enfoques de gerenciamento ambiental - relativos a posturas das empresas no que diz respeito a questões de meio ambiente -, foram identificados, a partir de estudos como os de Sobral, Hipel e Grahame (1981), Hunt e Auster (1990) e Cánepa (1991), três tipos básicos, com base na literatura técnica especializada:

. enfoque reativo;

. enfoque efetivo;

. enfoque pró-ativo.

Esta classificação, da mesma forma que a proposta para capacidade tecnológica, é progressiva. Assim, uma empresa que, em determinado momento, apresentar um enfoque reativo, poderá, através da assimilação de novas tecnologias e da ampliação de seus conceitos e habilidades sobre questões ambientais, passar aos demais enfoques.

O modelo proposto para análise de capacidade tecnológica e dos enfoques de gestão de resíduos sólidos em empresas calçadistas é apresentado nos Quadros 1, 2 e 3 . A partir do modelo, foi desenvolvido um questionário que considerava as variáveis de capacidade tecnológica e gestão de resíduos, constante dos respectivos quadros. Este questionário foi aplicado em duas empresas que serão denominadas A e B. A empresa A tem aproximadamente 1,2 mil funcionários. Produz, em média, 130 mil pares por mês, totalmente destinados à exportação, sendo mais de $50 \%$ correspondentes a modelos sociais, fechados, tipo mocassim, para o público feminino. Os respondentes, nesta empresa, foram os gerentes de Produção e de Qualidade, além de um Supervisor de Custos e um Técnico em Segurança do Trabalho. A empresa $\mathbf{B}$ tem um total de 1.885 funcionários, distribuídos entre matriz, onde o processo é completo, e duas filiais onde o processo não é completo. A média de produção de $\mathbf{B}$ é de aproximadamente 230 mil pares por mês - $99 \%$ destinados à exportação, predominando modelos sociais, fechados e abertos, para o público feminino. Na empresa $\mathbf{B}$, os respondentes foram gerentes de Produção e um Técnico em Segurança do Trabalho. 


\section{Quadro 1: Capacidade Tecnológica Básica e Enfoque Reativo de Gestão de Resíduos Sólidos}

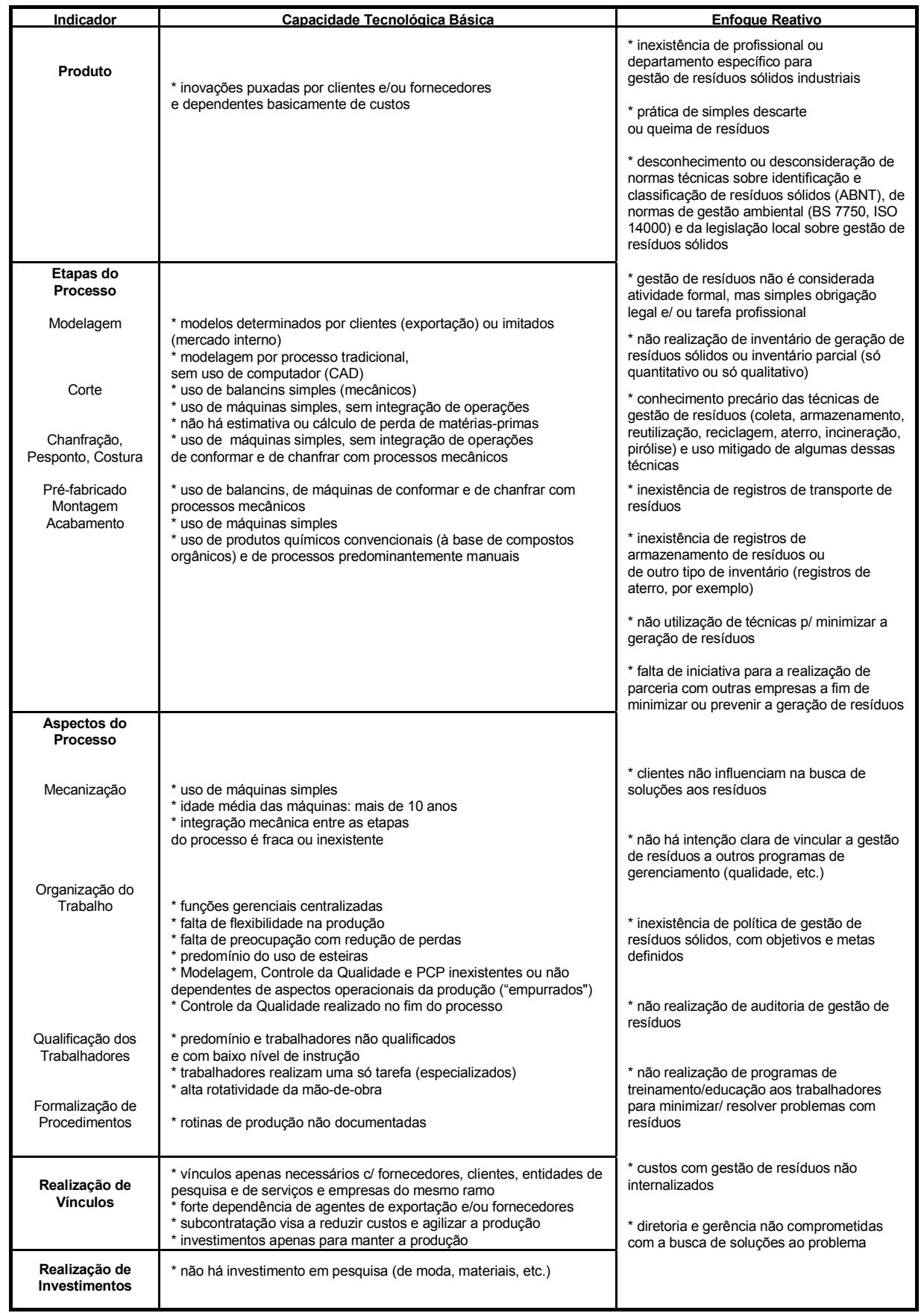




\section{Quadro 2: Capacidade Tecnológica Intermediária e Enfoque Efetivo de Gestão de Resíduos Sólidos}

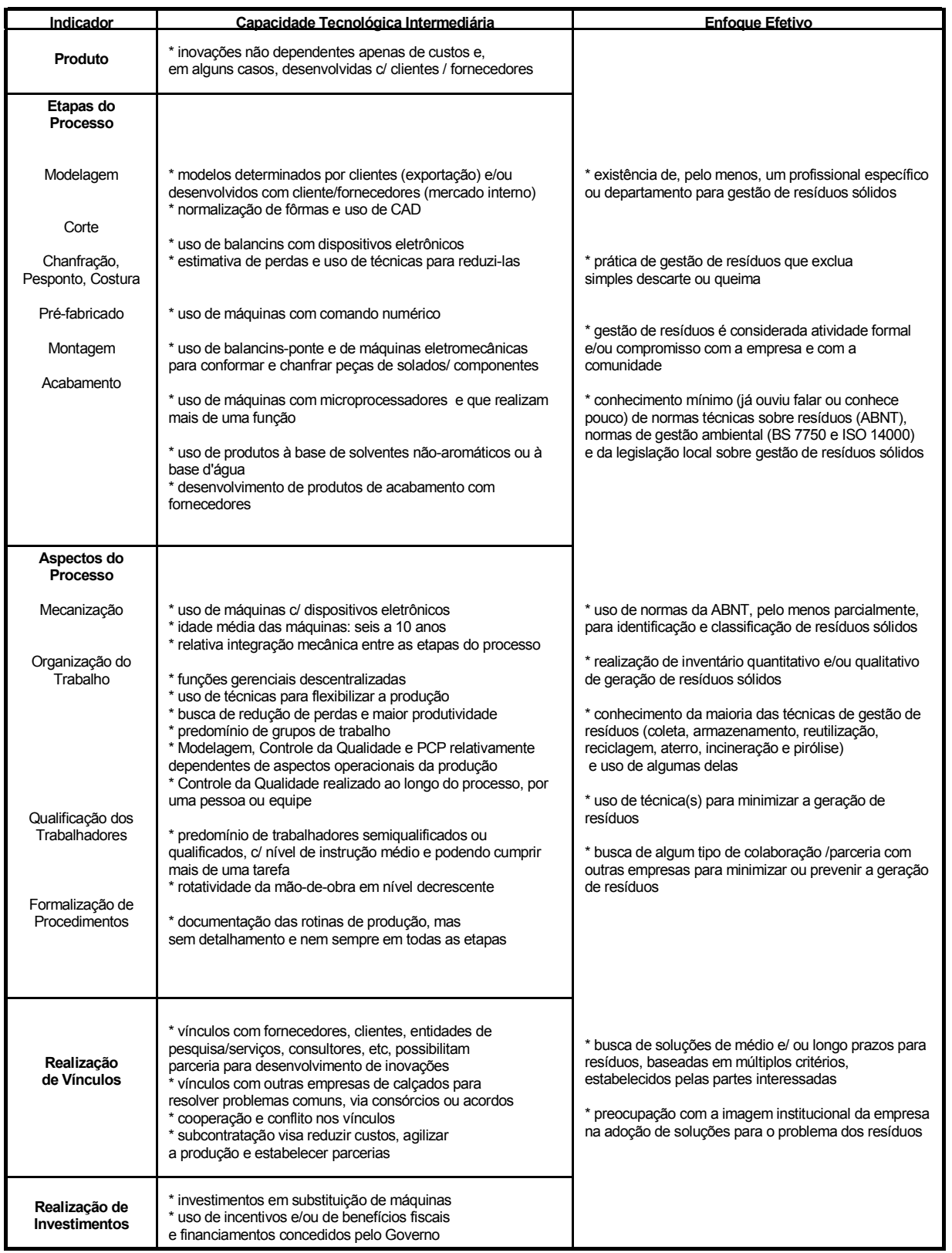




\section{Quadro 3: Capacidade Tecnológica Avançada e Enfoque Pró-ativo de Gestão de Resíduos Sólidos}

\begin{tabular}{|c|c|c|}
\hline Indicador & Capacidade Tecnológica Avancada & Enfoque Pró-ativo \\
\hline Produto & $\begin{array}{l}\text { * inovações não dependentes apenas de custos e } \\
\text { baseadas em pesquisas de moda }\end{array}$ & $\begin{array}{l}\text { * existência de profissional específico e departamento } \\
\text { para gestão de resíduos sólidos }\end{array}$ \\
\hline $\begin{array}{c}\text { Etapas do Processo } \\
\text { Modelagem } \\
\text { Corte } \\
\text { Chanfração, } \\
\text { Pesponto, Costura } \\
\text { Pré-fabricado } \\
\text { Montagem }\end{array}$ & $\begin{array}{l}\text { * modelos determinados por clientes (exportação) } \\
\text { e/ou desenvolvidos c/ clientes/ fornec. (merc. interno) } \\
\text { * uso de CAD/CAM, softwares p/ cálculo de custos } \\
\text { * uso de máquinas c/ corte a laser ou jato d'água } \\
\text { cálculo de perdas e uso de técnicas para reduzi-las } \\
\text { * uso de máquinas de costura c/ comando numérico } \\
\text { e com operações integradas } \\
\text { * uso de sistemas modernos, } \\
\text { interligando as operações do pré-fabricado } \\
\text { * uso de máquinas com microprocessadores } \\
\text { e que realizam mais de uma operação } \\
\text { * uso de produtos c/ solventes à base d'água } \\
\text { * pesquisa constante, junto c/ fornecedores, } \\
\text { p/ desenvolver novos produtos de acabamento }\end{array}$ & $\begin{array}{l}\text { * prática de gestão de resíduos que exclua simples } \\
\text { descarte ou queima e priorize reaproveitamento e } \\
\text { reciclagem } \\
\text { * gestão de resíduos é considerada atividade formal e } \\
\text { compromisso com a própria empresa e com a comunidade } \\
\text { * conhecimento e uso efetivo de normas técnicas de } \\
\text { classificação de resíduos (ABNT), de normas de gestão } \\
\text { ambiental (BS 7750, ISO 14000) e da legislação local } \\
\text { sobre } \\
\text { resíduos } \\
\text { * realização de inventário quantitativo e qualitativo sobre a } \\
\text { geração de resíduos sólidos } \\
\text { * conhecimento das técnicas de gestão de resíduos } \\
\text { (coleta, } \\
\text { armazenamento, reutilização, reciclagem, aterro, } \\
\text { incineração e pirólise) e uso das que ofereçam as } \\
\text { condições simultaneamente mais econômicas e ecológicas } \\
\text { * existência de registros completos de transporte de } \\
\text { resíduos } \\
\text { * existência de registros completos de armazenamento e } \\
\text { de outros tipos de inventário (aterro, por exemplo) }\end{array}$ \\
\hline $\begin{array}{l}\text { Qualificação dos } \\
\text { Trabalhadores } \\
\text { Formalização de } \\
\text { Procedimentos }\end{array}$ & $\begin{array}{l}\text { * uso de máquinas c/ softwares avançados } \\
\text { * idade média das máquinas: até } 5 \text { anos } \\
\text { * expressiva integração mecânica entre as etapas } \\
\text { * funções gerenciais descentralizadas } \\
\text { * programas avançados p/ aumentar produtividade e } \\
\text { reduzir perdas: Qualidade Total, JIT, Kanban, etc. } \\
\text { * predominam grupos de trabalho } \\
\text { * Modelagem, Controle da Qualidade e PCP totalmente } \\
\text { dependentes de aspectos operacionais da produção } \\
\text { * Controle da Qualidade realizado em todas as etapas do } \\
\text { processo, por todos os envolvidos na produção } \\
\text { * predomínio de trabalhadores qualificados, com nível de } \\
\text { instrução médio, que realizam várias tarefas } \\
\text { * baixos índices de rotatividade da mão-de-obra } \\
\text { * documentação detalhada das rotinas de produção } \\
\text { e em todas as etapas do processo }\end{array}$ & $\begin{array}{l}\text { * uso intensivo de técnicas avançadas para minimizar a } \\
\text { geração de resíduos } \\
\text { * existência de parceria entre a empresa e outras } \\
\text { empresas } \\
\text { para minimizar ou prevenir a geração de resíduos } \\
\text { * interação significativa com os clientes na busca de } \\
\text { soluções para problemas de resíduos sólidos } \\
\text { * gestão de resíduos sólidos já vinculada a outros } \\
\text { programas de gerenciamento (Qualidade Total, etc.) } \\
\text { *existência de uma política de gestão de resíduos sólidos, } \\
\text { com objetivos e metas definidos } \\
\text { * realização de auditoria de gestão de resíduos sólidos } \\
\text { * existência de programas formais de treinamento e de } \\
\text { educação ambiental aos funcionários, com ênfase em } \\
\text { resíduos }\end{array}$ \\
\hline $\begin{array}{l}\text { Realização de } \\
\text { Vínculos }\end{array}$ & $\begin{array}{l}\text { * vínculos com fornecedores, clientes, entidades de } \\
\text { pesquisa/serviços, consultores, etc. possibilitam } \\
\text { desenvolvimento de inovações, em parceria } \\
{ }^{*} \text { vínculos com empresas de calçados para resolver } \\
\text { problemas comuns/ consórcios } \\
\text { ^ subcontratação visa reduzir custos, agilizar a produção e } \\
\text { transferir tecnologia aos subcontratados } \\
\text { * ênfase aos vínculos para formação de mão-de-obra } \\
\text { especializada e desenvolvimento tecnológico }\end{array}$ & $\begin{array}{l}\text { * custos com gestão de resíduos totalmente internalizados } \\
\text { * busca de soluções de longo prazo para gestão de } \\
\text { resíduos, baseadas em métodos de prevenir o problema, } \\
\text { via alteração de processos, matérias-primas, etc. }\end{array}$ \\
\hline $\begin{array}{l}\text { Realização de } \\
\text { Investimentos }\end{array}$ & $\begin{array}{l}\text { *investimentos voltados predominantemente a inovações } \\
\text { em processos, com capital próprio, financiamento ou } \\
\text { através de joint ventures }\end{array}$ & $\begin{array}{l}\text { * preocupação com a formação de uma cultura de } \\
\text { preservação ambiental aliada a programas de qualidade }\end{array}$ \\
\hline
\end{tabular}




\section{Capacidade Tecnológica das Empresas}

Os questionamentos efetuados nas empresas resultaram nas seguintes constatações relativas à capacidade tecnológica:

\section{Produto:}

A empresa A produz sob encomenda para exportação, tendo os modelos determinados por clientes. A empresa $\mathbf{B}$ também produz sob encomenda, mas, de acordo com o Gerente de Produção, hoje consegue negociar com agentes de exportação visando à aceitação de modelos mais simples, com menos trabalho manual embutido e, portanto, com custos e desperdício menor de mão-de-obra. "Quanto mais mão-de-obra aplicada ao calçado, maior a geração de resíduos", explicou o gerente.

\section{Etapas do Processo:}

. Modelagem: O design dos modelos de A e de B é determinado por clientes. Em $\mathbf{A}$, não é utilizado $\mathrm{CAD}$, mas $\mathbf{B}$ utiliza esta tecnologia para corte de materiais sintéticos e tecidos. As máquinas desta etapa, em $\mathbf{A}$, têm idade de oito anos, em média e, em $\mathbf{B}$, de cinco anos.

Corte: São utilizadas máquinas com comando numérico em A e em B. A idade média é de 12 anos, em A, e de quatro anos, em B. O Gerente de Produção de B estima que as perdas caíram em torno de $6 \%$ com a implantação de um programa de combate ao desperdício de matérias-primas, envolvendo treinamento, desde 1996.

. Chanfração, pesponto e costura: As máquinas têm, em média, 12 anos, em A, e oito anos, em B. As de $\mathbf{B}$ são dotadas de dispositivos eletrônicos.

. Pré-fabricado: O sistema de pré-fabricado é simples, mas há máquinas dotadas de comando numérico em ambas as empresas.

. Montagem: As máquinas desta etapa têm, em média, 12 anos de idade, em A, e dois anos, em $\mathbf{B}$, onde apresentam dispositivos de microeletrônica.

. Acabamento: As máquinas têm idade média de 12 anos, em A, e de oito anos, em $\mathbf{B}$, que, nesta etapa, utiliza produtos desenvolvidos e testados em seu próprio laboratório.

\section{Aspectos do Processo:}

. Mecanização: Não há automação completa no processo produtivo, mas são utilizadas máquinas com dispositivos controlados por computador (comando 
numérico) em ambas as empresas. A idade média das máquinas, em geral, é de 11,5 anos na empresa A. Em B, a idade é de 5,4 anos.

- Organização do trabalho: Na empresa A, os departamentos de Modelagem, Controle da Qualidade (CQ) e Planejamento e Controle da Produção (PCP) são autônomos em relação às demais etapas do processo, mas interligados entre si por software. Em B, esses departamentos são interdependentes, mas há um controle centralizado. Em A, o controle da qualidade de produtos é realizado por todos os funcionários envolvidos diretamente na produção, durante o processo, mas existe ainda o revisor de fim de linha. Em B, o controle da qualidade é realizado apenas por funcionários do departamento específico e no fim do processo. Recentemente, no entanto, foi implantado em B um sistema de avaliação da qualidade dos produtos que envolve equipes variáveis, de cinco pessoas, pertencentes aos diversos setores da empresa. Esses grupos se reúnem três vezes por semana para analisar a qualidade de cinco modelos extraídos aleatoriamente da produção. Os resultados da avaliação são levados aos supervisores de linha, com sugestões de melhorias.

Em A, a forma de organização do trabalho é mista. Há esteiras, na Montagem e no Acabamento, e grupos de trabalho, no Corte e na Costura. Segundo o Gerente de Produção, após a implantação dos grupos, a produtividade, na Costura, aumentou 15\%. Em B, a forma predominante de organização do trabalho é através de esteiras. Há grupos de trabalho apenas no Corte.

. Qualificação dos trabalhadores: Em A, 0,4\% dos trabalhadores empregados diretamente na produção têm qualificação técnica obtida através de cursos profissionalizantes. Em B, este percentual é de $0,83 \%$. Os analfabetos são $0,2 \%$ em A e 0,89\% em B; os semi-alfabetizados são 0,4\% em A e 34,22\% em B. Têm $1^{\circ}$ grau incompleto, $35 \%$ em A e $29 \%$ em B. Têm $1^{\circ}$ grau completo, $34 \%$ em A e 18,92\% em B. Têm $2^{\circ}$ grau incompleto, $18 \%$ em A e $14,47 \%$ em B. Têm $2^{\circ}$ Grau completo; 8,4\%, em A e 1,67\%, em B.

Em A, há poucos trabalhadores especializados, pois a maioria exerce mais de uma função, e é possível que todos sejam deslocados para atuar em outro setor. Em B, apenas os trabalhadores do Corte são especializados.

O nível de rotatividade da mão-de-obra se mantém em aproximadamente $2,5 \%$ do total de empregados em A e, em B, oscila de 1,66\% a 6,59\%.

. Formalização de procedimentos: Em A, existe formalização das rotinas de produção, através de documentos, há cerca de 15 anos, mas esses registros são feitos pelo pessoal do setor de Planejamento e Controle da Produção (PCP), sem participação dos operários de chão-de-fábrica. Há quase dois anos, porém, teve início a documentação das rotinas de produção pelos trabalhadores 
envolvidos diretamente na produção. Em B, não há participação dos trabalhadores neste processo.

Vínculos: Os agentes com quem as empresas $\mathbf{A}\left({ }^{*}\right)$ e $\mathbf{B}\left({ }^{* *}\right)$ mantêm relações e as respectivas finalidades podem ser visualizados no quadro a seguir.

\section{Quadro 4: Vínculos das Empresas A e B}

\begin{tabular}{|c|c|c|c|c|c|c|c|c|c|}
\hline $\begin{array}{l}\text { Parcerias } \\
\text { com }\end{array}$ & $\begin{array}{l}\text { Fornece- } \\
\text { dores de } \\
\text { insumos } \\
\text { químicos }\end{array}$ & $\begin{array}{l}\text { Fornece- } \\
\text { dores de } \\
\text { máq/equi- } \\
\text { pamentos }\end{array}$ & $\begin{array}{l}\text { Fornece- } \\
\text { dores de } \\
\text { matérias } \\
\text {-primas } \\
\end{array}$ & $\begin{array}{l}\text { Fornece- } \\
\text { dores de } \\
\text { compo- } \\
\text { nentes } \\
\end{array}$ & $\begin{array}{l}\text { Fabrican- } \\
\text { tes de } \\
\text { calçados }\end{array}$ & $\begin{array}{l}\text { Institu- } \\
\text { tos de } \\
\text { ens./pesq. }\end{array}$ & $\begin{array}{l}\text { Agentes } \\
\text { de } \\
\text { export. }\end{array}$ & $\begin{array}{l}\text { Consul- } \\
\text { tores }\end{array}$ & $\begin{array}{l}\text { Subcon- } \\
\text { tratados }\end{array}$ \\
\hline \multicolumn{10}{|l|}{ Finalidade } \\
\hline $\begin{array}{l}\text { Melhorar } \\
\text { negociacões mútuas }\end{array}$ & & & $*$ & $*$ & & & $*$ & & \\
\hline $\begin{array}{l}\text { Desenvolver prod/ } \\
\text { processos }\end{array}$ & & $*$ & & & & & * & * & \\
\hline $\begin{array}{l}\text { Comprar } \\
\text { máq/equipamentos }\end{array}$ & & ** & & & & & & & \\
\hline \multicolumn{10}{|l|}{$\begin{array}{l}\text { Realizar programas } \\
\text { de OT }\end{array}$} \\
\hline Formar mão-de-obra & $*$ & & & & & * & & * & \\
\hline \multicolumn{10}{|l|}{ Agilizar a produção } \\
\hline Reduzir perdas & $*$ & $*$ & * & * & $*$ & $*$ & $* *$ & & \\
\hline Testar produtos & $*$ & $*$ & $*$ & $*$ & $*$ & $*$ & $*$ & & \\
\hline Outra (especificar) & $*$ (a) & & & & $* *(\mathrm{c})$ & & & $*(\mathrm{~b})$ & \\
\hline
\end{tabular}

Finalidade dos vínculos: (a) empréstimos de máquinas e matérias-primas

(b) realização de Controle da Qualidade

(c) melhoria do sistema de produção e gerenciamento de resíduos sólidos

Investimentos: $\mathrm{Na}$ empresa $\mathbf{A}$, não são realizados investimentos em $\mathrm{P} \& \mathrm{D}$ de novos produtos e processos. Em $\mathbf{B}$, gerentes informaram que são realizados investimentos em $\mathrm{P} \& \mathrm{D}$ de novos processos, no interior da própria empresa, para agilizar a produção e reduzir o contingente de mão-de-obra ocupada, mas não revelaram o montante ou a proporção desses investimentos sobre seu faturamento, nem detalharam em que processos investem. Sabe-se que há, em B, um laboratório, onde são desenvolvidos acabamentos e adesivos e realizados alguns testes em componentes do calçado.

Através dessas informações, pode-se concluir que a capacidade tecnológica das empresas ainda é básica, embora haja esforços de melhoria que podem ser detectados através dos seguintes itens:

. em A, recente introdução da documentação de rotinas que envolve os trabalhadores da produção; intenção de estender os grupos de trabalho à Montagem; capacidade expressiva de realização de vínculos com outros agentes, especial- 
mente com fornecedores de máquinas e equipamentos, com agentes de exportação e consultores, em relação aos quais foi informada a existência de cooperação para introdução de inovações em produtos e processos; existência de funcionários, em sua maioria com capacidade para operar em várias etapas do processo;

. em B, predomínio de máquinas novas no processo, com recursos avançados, que permitem a integração de algumas rotinas e a realização de mais de uma tarefa com a mesma máquina; extensão do controle da qualidade de produtos a equipes de vários setores; redução das perdas de matérias-primas a partir de controle rigoroso do seu consumo e do treinamento de pessoal envolvido diretamente na produção; troca de informações com fabricantes de calçados para melhorias no processo; relativa capacidade de negociação com agentes de exportação para simplificar modelos, reduzindo perdas de materiais e custos de produção; realização de investimentos em pesquisa aplicada, através do laboratório próprio, para melhoria de produtos e racionalização do uso da mão-deobra.

\section{Gestão de Resíduos Sólidos}

A avaliação da gestão de resíduos sólidos realizada junto aos respondentes permitiu a obtenção dos seguintes resultados:

. Existência de profissional específico para gestão de resíduos: As empresas A e B não têm profissional atuando exclusivamente na empresa, em tempo integral, para administrar problemas de resíduos sólidos industriais, nem departamentos específicos, mas apenas um consultor, que presta assessoria à empresa, quando necessário.

. Prática de simples descarte e/ou queima: Esta prática foi comum às duas empresas até 1992, quando, pressionadas pela legislação ambiental, adotaram uma solução em conjunto com outras três empresas, instalando um aterro coletivo.

. Enfoque da gestão de resíduos pela empresa: Em A, os gerentes informaram que a gestão de resíduos é vista pela empresa como uma obrigação legal, uma atividade formal e um compromisso com a própria empresa e com a comunidade. Em B, os respectivos gerentes informaram que a gestão de resíduos é vista pela empresa como simples tarefa profissional, sendo enfatizado o treinamento dos empregados que fazem a coleta.

. Conhecimento e uso das normas técnicas sobre identificação e classificação de resíduos sólidos, das normas de gestão ambiental e da legislação sobre resíduos sólidos: Os gerentes de $\mathbf{A}$ e de $\mathbf{B}$ assinalaram que conhecem e 
usam as seguintes técnicas: coleta, identificação, separação, transporte, armazenamento e aterro. Os de $\mathbf{A}$ afirmaram apenas conhecer incineração e informaram não conhecer e não empregar reutilização, reciclagem e pirólise. Os de B revelaram não conhecer e não utilizar reciclagem, incineração e pirólise. Os de A afirmaram conhecer pouco sobre normas da ABNT para classificação de resíduos e sobre a Lei estadual 9.921/93, relativa a resíduos sólidos. Os de $\mathbf{B}$ não informaram sobre seu conhecimento relativo às normas da $\mathrm{ABNT}$ para classificação de resíduos, à Lei 9.921/93 e a normas de gestão ambiental.

Em ambas as empresas, porém, há separação de resíduos no interior das unidades de produção. São destinados à venda ou armazenamento resíduos de papel, papelão, plásticos, algumas borrachas e metais. São destinados a aterro resíduos de couro curtido, pó de varrição, restos de adesivos e estopas e esponjas sujas com adesivos e produtos químicos e a maioria dos restos de solados, viras e contrafortes.

. Registros de armazenamento e/ou aterro (inventários): Em ambas as empresas, há registros de armazenamento e aterro de resíduos desde setembro de 1994, realizados por consultores e funcionários da empresa contratados para cuidar do armazenamento e do aterro. Porém não é realizado um inventário de matérias-primas para cada etapa do processo produtivo. Resultados de cálculos, a partir dos registros de armazenamento e aterro, mostram que a geração de resíduos por par em períodos idênticos diminuiu 53,76\% em B, em um comparativo de 12 meses correspondentes, e aumentou 1,16\% em A. Nesse mesmo período, a produção de $\mathbf{A}$, em número de pares, caiu $0,69 \%$, e a de $\mathbf{B}$ subiu $70 \%$.

- Uso de técnicas para minimizar a geração de resíduos: A realiza programas de instrução aos trabalhadores, para que eles racionalizem matérias-primas e separem os resíduos. Na central de resíduos, é feita a compactação de materiais recicláveis, antes do armazenamento, para minimizar os volumes. A empresa B utiliza o CAD, na produção; realiza treinamento de pessoal, principalmente no corte, e faz um rigoroso controle de qualidade das matérias-primas.

. Parcerias para minimizar ou prevenir a geração de resíduos sólidos: A não mantém parcerias com outras empresas de calçados para discussão de formas de prevenir e/ou minimizar o problema dos resíduos sólidos. $\mathbf{B}$ recorre a outros fabricantes de calçados, a fornecedores e a um centro de pesquisas aplicadas, para buscar soluções para seus problemas de resíduos. Em ambos os casos, os clientes não têm nenhuma influência nas decisões das empresas quanto à busca de soluções para o problema dos resíduos sólidos. "Os clientes querem saber as especificações corretas dos produtos, não dos restos da produção", disse um gerente de B. 
. Existência de uma política de gestão de resíduos sólidos: As empresas não têm políticas próprias de gestão de resíduos sólidos industriais, com objetivos e metas definidos.

. Realização de auditoria de gestão de resíduos sólidos: As empresas não realizam auditoria ambiental e/ou de resíduos sólidos.

. Realização de programa formal de educação ambiental: As empresas não têm programa formal de educação e/ou treinamento para a área ambiental, que inclua o problema dos resíduos. A empresa $\mathbf{B}$, porém, pretende realizar um trabalho sobre desperdícios, envolvendo os setores de custos e cronometragem.

\section{. Preocupação com a formação de uma cultura ambiental aliada a progra-} mas de qualidade: Ao programa de qualidade desenvolvido por $\mathbf{A}$, que visa à certificação pelas normas ISO 9000, deverão ser incorporados aspectos de gestão de resíduos. Já em $\mathbf{B}$, os gerentes revelaram que seu programa de qualidade não é documentado, nem vinculado diretamente ao problema dos resíduos sólidos.

Os resultados permitem concluir que ainda predomina o enfoque reativo de gestão de resíduos em ambas as empresas, devido às seguintes características:

. Em A e B: falta um profissional ou departamento específico para gestão de resíduos; grande parte das soluções adotadas para resolver o problema é motivada por exigências legais; não há conhecimento profundo de normas técnicas sobre resíduos (ABNT) e da legislação estadual sobre o assunto, e há desconhecimento das normas de gestão ambiental (BS 7750 e ISO 14000); os registros relativos a resíduos não são rigorosamente controlados nem analisados em relação à produção de pares, e referem-se apenas a armazenamento e aterro; além disto, não é documentada, rigorosamente, a saída dos resíduos da unidade de armazenamento; não há uma política formal de gestão de resíduos, com objetivos e metas definidos, nem realização de auditoria nesta área.

. Especificamente em A: os gerentes informaram não conhecer nem fazer uso da técnica de reutilização, quando, na verdade, esta técnica é empregada no treinamento de mão-de-obra com restos de couro; apesar de ter informado que a empresa tem vínculos com fornecedores de produtos químicos, máquinas, outros fabricantes de calçados e entidades de pesquisa, visando à redução de perdas, um dos gerentes revelou que não são discutidos problemas relacionados a resíduos com clientes ou com outros agentes - exceto com empresas do mesmo ramo, para realização de aterro; isto pode indicar que as parcerias estão mais centradas na busca da redução de custos monetários - 
em um enfoque exclusivamente econômico - do que na busca da redução de custos ambientais, já que esta incluiria não só o máximo esforço em minimizar a geração de resíduos, mas soluções que ensejassem um impacto ambiental menor que o derivado do simples armazenamento ou do aterro, até com possibilidade de ganhos por reciclagem ou reaproveitamento; não há programa formal de treinamento ou educação ambiental dos funcionários.

. Especificamente em B: a gestão de resíduos não é considerada atividade formal na empresa, tanto que os registros quantitativos (inventários), o conhecimento de normas técnicas, normas de gestão ambiental e legislação sobre resíduos, bem como a distinção entre o que é e o que não é reciclável, consideram-se atribuições de uma empresa especialmente contratada para esta finalidade.

\section{Análise Comparativa das Empresas}

As empresas A e B, tipificadas, através de análises anteriores, como empresas de capacidade tecnológica básica que apresentam elementos de transição para uma capacidade intermediária, e como empresas que adotam, na prática, um enfoque predominantemente reativo de gestão de resíduos sólidos, apresentam uma série de diferenças quando se considera o estabelecimento das relações entre o uso das tecnologias de produção e o modo de gestão dos resíduos sólidos. Tais diferenças decorrem do fato de que nem sempre compartilham as mesmas opções no que diz respeito ao uso de técnicas, conhecimentos, habilidades e experiências.

As análises anteriores deixam claro que a empresa $\mathbf{A}$ enfatiza mais que $\mathbf{B}$ a participação dos funcionários no processo produtivo e a realização de vínculos com outros agentes da cadeia produtiva. São exemplos disto a participação de todos os funcionários no controle da qualidade, o início de um processo de documentação de rotinas de produção com a participação dos empregados, a predominância dos grupos na organização do trabalho e a formação de parcerias com vários agentes, para várias finalidades - testar produtos, agilizar a produção, formar mão-de-obra, reduzir perdas, etc. Esses atributos são considerados menos importantes em $\mathbf{B}$, onde nem todos os empregados participam do controle da qualidade no processo, as rotinas de produção são tarefa apenas do setor de Planejamento e Controle da Produção, os grupos de trabalho existem apenas no corte e, praticamente, não são mantidos vínculos de parceria com outros agentes. Além disto, em relação a $\mathbf{B}, \mathbf{A}$ tem maior proporção de trabalhadores com escolaridade de $1^{\circ}$ e $2^{\circ}$ graus e tem menor percentual de analfabetos $-0,20 \%$, contra $0,89 \%$, de B - e de semi-alfabetizados $-0,40 \%$ em face de $34,22 \%$, de $\mathbf{B}$.

Em compensação, os responsáveis pela produção, em $\mathbf{B}$, enfatizam mais que os 
gerentes de $\mathbf{A}$ os aspectos pesados da tecnologia, principalmente a renovação das máquinas e equipamentos, que têm idade média de 5,4 anos, contra 11,5 anos, em $\mathbf{A}$; a formação estritamente técnica - que atinge $0,83 \%$ da mão-de-obra de $\mathbf{B}$, contra $0,40 \%$ dos trabalhadores de $\mathbf{A}-;$ a incorporação às máquinas de recursos de automação, que possibilitam a integração de algumas etapas do processo; e os investimentos em pesquisa, visando a incrementar essa integração e, ao mesmo tempo, a reduzir o contingente de mão-de-obra ocupado e a melhorar a qualidade dos produtos e processos.

Portanto, no que diz respeito à capacidade tecnológica, as respostas aos indicadores estabelecidos mostram que as estratégias dos gerentes de $\mathbf{A}$ estão voltadas mais à busca da produtividade mediante a integração do pessoal empregado do que à obtenção de vantagens por meio da mecanização e da intensificação do trabalho em esteiras. Em B, pelo contrário, as respostas dos gerentes aos indicadores mostram interesse quanto à busca de sistemas de produção com crescente eficiência baseada no enxugamento do uso da mão-de-obra e em técnicas de redução dos estoques intermediários e do tempo de passagem dos produtos.

Considerando-se esses diferenciais entre $\mathbf{A}$ e $\mathbf{B}$, quanto ao uso de tecnologias de produção, é possível compreender por que, mesmo com seus gerentes adotando soluções idênticas para resolver seus problemas com resíduos sólidos industriais - basicamente, armazenamento e aterro -, as duas empresas apresentam diferenças significativas em termos de organização das funções de gestão dos resíduos e de desempenho quanto às variações percentuais em termos de quantidades de rejeitos industriais gerados, comparativamente às respectivas produções, em idênticos períodos de análise.

\section{CONCLUSÕES}

A indústria calçadista brasileira de exportação vem sustentando seus ganhos de produtividade basicamente por meio das estratégias de redução e diferenciação de produto, o que pode ser demonstrado pelos ganhos de escala na produção (que resultam diminuição de custos) e pela segmentação de mercados (que implica diferenciação). Os métodos para obter reduções de custos e produtos sempre diferenciados, porém, nem sempre estão vinculados aos aspectos sistêmicos de competitividade, que incluem a variável meio ambiente. Isto significa que nem sempre a queda de custos e/ou a diferenciação partem do pressuposto de um benefício ambiental ou resultam em ganho ambiental, mas, pelo contrário, são, normalmente, estratégias estabelecidas e cumpridas à revelia do problema ambiental - no caso o problema da geração de resíduos. Esta falta de vínculo entre o uso 
de estratégias de competitividade e a preservação ambiental é marcante na cultura empresarial do setor, e é especialmente importante para que se possa compreender por que a busca de soluções para problemas de resíduos sólidos, no ramo de calçados, ainda está em um estágio no qual as empresas dependem basicamente de apoio de consultores especializados.

Observou-se, pelos resultados obtidos no estudo, que os gerentes das empresas A e B têm pouco interesse ou estão pouco empenhados em viabilizar soluções que levem ao reaproveitamento ou à reciclagem e em realizar ou financiar estudos que considerem, ao mesmo tempo, a viabilidade econômica e ambiental de alternativas ao aterro e ao armazenamento. Constatou-se que os gerentes de $\mathbf{A}$ exploram mais os aspectos da capacidade tecnológica ligados, internamente, à organização e à valorização do potencial formal dos recursos humanos e, externamente, à realização de vínculos. São exemplos disto, em nível interno, o gerenciamento das rotinas de produção com a participação dos trabalhadores, a intenção de incrementar a utilização dos grupos de trabalho e o baixo índice de analfabetos e semi-alfabetizados empregados e, em nível externo, as ligações com agentes de vários segmentos, para absorver e/ou desenvolver inovações. Em contrapartida, os aspectos pesados da capacidade tecnológica, ligados à formação estritamente técnica da mão-de-obra e, especialmente, ao uso de máquinas e equipamentos, são pouco evidenciados em $\mathbf{A}$, onde o percentual de funcionários com curso técnico é inferior à $\mathbf{B}$ e onde as máquinas têm idade média superior a 10 anos, não há uso de CAD, e a integração dos processos, por dispositivos automatizados, é muito fraca.

No caso de $\mathbf{B}$, verificou-se que, ao contrário de $\mathbf{A}$, os aspectos da capacidade tecnológica vinculados, internamente, ao potencial formal dos recursos humanos, e externamente, à efetivação de vínculos, são menos enfatizados perante os aspectos tecnológicos dependentes da organização do trabalho e do uso de máquinas e equipamentos modernos e integrados, para garantir ganhos de produtividade. Isto fica evidente à medida que $\mathbf{B}$ apresenta um percentual expressivo de semi-alfabetizados, ao mesmo tempo que um índice de qualificação técnica de seus empregados superior ao de A. Fica claro, também, pelas informações, que os gerentes de B apostam mais em pesquisa interna para desenvolver acabamentos e melhorar processos do que no estabelecimento de vínculos para inovações e que adotam um sistema de produção com máquinas relativamente novas - mesmo no Corte-, que agregam tecnologias capazes de permitir uma boa integração entre as etapas produtivas. Os avanços na automação, simultaneamente à intensificação do trabalho nas esteiras, assegura ganhos de escala à empresa $\mathbf{B}$.

Essas diferenças entre $\mathbf{A}$ e $\mathbf{B}$, quanto às opções e ênfases no uso de tecnologias, poderiam explicar por que $\mathbf{B}$ obteve melhor desempenho do que $\mathbf{A}$ em termos de 
redução de geração de resíduos por par, no período analisado. Poderia explicar também por que os gerentes de A declaram ser a gestão de resíduos "um compromisso com a empresa e com a comunidade", enquanto que os gerentes de $\mathbf{B}$ afirmam considerar este tipo de gestão de forma mais técnica, como "simples tarefa profissional".

No que diz respeito ao modelo de análise de capacidade tecnológica, evidenciase que este mostrou ser útil para futuras investigações. Sugere-se, porém, que o modelo seja submetido à análise de uma gama variada de profissionais ligados à cadeia produtiva do calçado e ao desenvolvimento tecnológico do setor, a fim de que os indicadores nele contidos possam ser ponderados quantitativamente, estabelecendo-se a importância proporcional de cada um na avaliação da capacidade tecnológica das empresas de calçados. Esta avaliação crítica dos indicadores propostos seria especialmente relevante antes da sua aplicação a um maior número de empresas.

Em resumo, o estudo dos dois casos evidenciou que as empresas, apesar de enquadráveis no mesmo nível de capacidade tecnológica, apresentam diferenças de desempenho tecnológico entre si, que podem afetar os resultados em termos de gerenciamento de resíduos sólidos industriais. Os resultados sugerem ainda que as melhorias promovidas na capacidade tecnológica podem condicionar, mas não necessariamente determinar, o bom desempenho em termos de gerenciamento de resíduos sólidos nas empresas.

\section{REFERENCIAS BibLIOGRÁfICAS}

ALVES FILHO, A. G.

Estratégia tecnológica, desempenho e mudança : estudo de caso em empresas da indústria de calçados. São Paulo, 1991. Tese (Doutorado) - Universidade de São Paulo.

\section{CÁNEPA, E. M.}

A problemática ambiental e a função do estado numa economia mista moderna. Ensaios FEE, v. 11, n. 2, p. 251-279, 1991.

ASSOCIAČ̃̃O BRASILEIRA DAS INDUSTRİAS DE CALÇADOS.

Desempenho das exportações brasileiras - 1994 a agosto de 1996. Novo Hamburgo, 1996. (mimeo).

CENTRO TECNOLÓGICO DO COURO, CALÇADOS E AFINS e SERVIÇO BRASILEIRO DE APOIO ÀS MICRO E PEQUENAS EMPRESAS.

A fabricação do calçado. Novo Hamburgo, 1994. v. 3.

COSTA, A. B. DA.

Modernização e competitividade da indústria de calçados brasileira. Rio de Janeiro, 1993. 
COUTINHO, L.;

FERRAZ, J. C.

Estudo da competitividade da indústria brasileira. São Paulo : Unicamp, 1994.

CRUZ, H. N. DA.

Alternativas e difusão tecnológicas : o caso do setor de calçados do Brasil. São Paulo, 1976. Tese (Doutorado) - Universidade de São Paulo.

GOMES NETO, J.;

FIGUEIREDO, K. F.

As mudanças tecnológicas promovidas pelas empresas brasileiras produtoras de calçados e o desempenho nas atividades de exportação. Relatório de Pesquisa n. 38. Rio de Janeiro, 1982.

HUNT, C. B.;

AUSTER, E. R.

Proactive environmental management : avoiding the toxic trap. Sloan Management Review, v. 31, n. 2, Winter 1990.

\section{LALL, S.}

Tecnhological capabilities and industrialization. World Development, v. 20, n. 2, 1992.

MOREIRA, E. M.

O nível de inovação tecnológica da indústria de calçados de couro do Vale do Sinos: determinantes e tendências a inovar. Porto Alegre, 1987. Dissertação (Mestrado) - Universidade Federal do Rio Grande do Sul.

NOER, R.

Realização de melhorias na indústria mineral e calçadista com apoio de sistemas de informações a partir das exigências da Legislação Ambiental. Porto Alegre, 1995. Dissertação
(Mestrado em Administração) Programa de Pós-Graduação em Administração, Universidade Federal do Rio Grande do Sul.

\section{PICCININI, V.}

L'industrie de la chaussure brésilienne face aux mutations internationales : stratégies et politique du personnel des entrerprises de la région de Vale do Sinos. Grenoble, 1990. Thèse (Doctorat) - Université de Grenoble.

Novas formas de organização do trabalho na indústria calçadista. In: XVI SIMPÓSIO NACIONAL DE PESQUISA DE ADMINISTRACCAOO EM CIENCIA \& TECNOLOGIA (1991 : Rio de Janeiro). Anais ... São Paulo : 1991. p. 158-165.

Tecnologia, processo de trabalho e qualificação profissional. In: XVII ENCONTRO ANUAL DA ANPAD (1993 : Salvador). Anais ... Salvador : ANPAD, 1993. p. 292-307.

PORTER, M.;

LINDE, C. V.

Ser verde também é ser competitivo. Exame, São Paulo, set. 1995.

REIS, C. N. DOS.

$A$ indústria brasileira de calçados: inserção internacional e dinâmica interna nos anos 80 . São Paulo, 1994. Tese (Doutorado) Universidade de São Paulo.

RUAS, R. L.

Efeitos da modernização sobre o processo de trabalho - condiçốes objetivas de controle na indústria de calçados. Porto Alegre : Fundação de Economia e Estatística do Rio Grande do Sul, 1985. 
RUAS, R. L.;

ANTUNES, E. D. D.

$O$ conceito de cluster e as relações interfirmas no complexo calçadista do Rio Grande do Sul. Porto Alegre : Universidade Federal do Rio Grande do Sul, 1992. (mimeo).

\section{SEBRAE/SCT.}

Tecnologia e competitividade : análise e perspectiva da indústria calçadista do Rio Grande do Sul. Porto Alegre : Serviço de Apoio às Micro e Pequenas Empresas do Rio Grande do Sul/ Secretaria de Ciência e Tecnologia do Rio Grande do Sul, 1992.

SILVEIRA, C. E. F. (Org.)

Subsídios para uma política tecnológica para a indústria de calçados de couro de Franca. São Paulo : Instituto de Pesquisas Tecnológicas (IPT) de Franca, 1986.

SOBRAL, M. M.; HIPEL, K. W. F.; GRAHAME, J.

A multi-criteria model for solid waste management. Journal of Environmental Management, v. 12, p. 97-110, 1981.

ZAWISLAK, P. A.

L'activité de conception - les trajectoires brésiliennes de l'industrie aéronautique et de l'industrie de la chaussure. Paris, 1994. Thèse (Doctorat). 